\title{
Effect of High Dose Thiamine Therapy on Risk Factors in Type 2 Diabetics Saadia Shahzad Alam ${ }^{1}$, Samreen Riaz ${ }^{2 *}$ and Waheed Akhtar M $^{3}$
}

${ }^{1}$ Department of Pharmacology, Federal Postgraduate Medical Institute, Lahore, Pakistan

2University College London, UK

${ }^{3}$ School of Biological Sciences University of the Punjab, Lahore, Pakistan

\begin{abstract}
Background: Traditional and more recently, a host of nontraditional risk factors of type 2 diabetes mellitus have adopted significance as promoters of the pathologies associated with this disease. High dose Vitamin B1 (thiamine) has been found at preclinical level to play an ameliorative role through a number of intracellular metabolic pathways. In order to demonstrate this clinically, pioneering research on the effect of high dose thiamine on associated markers of biochemical dysfunction, incipient diabetic nephropathy, hemostasis (plasminogen activation inhibitor/PAI-1), oxidative stress (plasma thiols) and second messenger signaling (protein kinase C/ PKC ) was conducted.
\end{abstract}

Subjects and methods: Type 2 diabetics were enrolled in randomized, double blind placebo controlled clinical trial for 6 months. Patients were divided into two groups and administered $300 \mathrm{mg} /$ day thiamine or placebo for 3 months, followed by a 2 month washout period. Normal healthy controls participated for baseline estimations only. Plasma and urinary thiamine levels, microalbuminuria, PAI-1, oxidative stress marker plasma thiols were estimated. The messenger signaling PKC profile was determined in normal controls and in type 2 diabetics.

Results: Lower plasma thiamine concentration of diabetic patients was observed as compared to normal subjects. Thiamine treatment increased thiamine concentration and urinary thiamine excretion and reduced significantly microalbuminuria and glycated hemoglobin. Type 2 diabetics had significantly higher PAI-1 and PKC levels as compared to normal controls. Following 3 months thiamine therapy, PAl-1 remained unchanged, while levels of PKC were reduced significantly in thiamine treated diabetics and lowered after discontinuing the drug While in placebo group significant increase in PKC levels persisted during the whole period. Oxidative stress marker, plasma thiols was reduced significantly in diabetics versus normal controls with no change occurring following thiamine or placebo therapy.

Conclusion: Thiamine therapy significantly improved micoalbuminuria, glycated hemoglobin, thiamine status and decreased PKC levels with no significant impact on oxidative stress and fibrinolysis profile.

Keywords: Type 2 diabetes mellitus; Thiamine; Micoalbuminuria; Protein kinase C

\section{Background}

International statistics elucidate that 3.2 million people died of diabetes each year and 6 people die of diabetes related ailments each minute [1]. Individuals with type 2 diabetes have 2-4 times more heart disease at an earlier age and a two times higher risk of stroke than non-diabetics [2]. Diabetes ranks second in causation of retinopathy leading to loss of vision and incipient and overt nephropathy worldwide [2]. Thus a disproportionate increase in the tendency towards life threatening conditions is observed in diabetics emanating from microvascular and macrovascular angiopathies which appear to be linked to certain risk factors and altered intracellular signaling mechanisms [3].

It is believed that hyperglycemia is one of the most important metabolic factors in the development of both micro- and macrovascular complications in diabetic patients. Several prominent hypotheses exist to explain the adverse effect of hyperglycemia [4]. One of them is the chronic activation by hyperglycemia of protein kinase (PKC) [5] a family of enzymes that are involved in controlling the function of other proteins. PKC has been associated with vascular alterations such as increases in permeability, contractility, extracellular matrix synthesis, cell growth and apoptosis, angiogenesis, leukocyte adhesion, and cytokine activation and inhibition [6]. These perturbations in vascular cell homeostasis caused by different PKC isoforms (PKC- $\alpha,-\beta 1 / 2$, and PKC- $\delta$ ) are linked to the development of pathologies affecting large vessel (atherosclerosis, cardiomyopathy) andsmallvessel (retinopathy, nephropathyandneuropathy) complications [7-9].
An important determinant of hemostasis, the endogenous fibrinolytic system represents a balance between activators of plasminogen (primarily tissue plasminogen activator) and inhibitors of these activators (such as plasminogen inhibitor type 1, PAI-1) [10]. Impaired fibrinolytic function in diabetes correlates with the severity of vascular disease and is a risk factor for myocardial infarction in both diabetic and non diabetic subjects [11-15]. Coagulation disorders have also been reported in type 2 diabetics ranging from alterations in VWF antigen and, factors [2,5,7] with decreased antithrombin 3 [16]. The importance of the endothelium in maintaining vascular health has also been widely recognized and assessment of its specific biomarkers reveals raised and Human soluble Vascular Adhesion Molecule-1 (Human sVCAM-1) levels and VWF: Von Willebrand Factor levels in type 2 diabetes as compared to normal controls. Our own previously published work in Diabetologia corroborates the results $[17,18]$ and reports a decrease in their levels following high dose thiamine intervention.

*Corresponding author: Samreen Riaz, University College London, UK, E-mail: drsamreenriaz@hotmail.com

Received October 13, 2012; Accepted November 24, 2012; Published November 30,2012

Citation: Alam SS, Riaz S, Waheed Akhtar M (2012) Effect of High Dose Thiamine Therapy on Risk Factors in Type 2 Diabetics. J Diabetes Metab 3: 233 doi:10.4172/2155-6156.1000233

Copyright: @ 2012 Alam SS, et al. This is an open-access article distributed unde the terms of the Creative Commons Attribution License, which permits unrestricted use, distribution, and reproduction in any medium, provided the original author and source are credited. 
Oxidative stress additionally plays a pivotal role in the development of diabetes complications especially angiopathies. The metabolic abnormalities of diabetes, predominantly hyperglycemia, cause mitochondrial superoxide overproduction in endothelial cells of both large and small vessels, as well as in the myocardium. This enhanced superoxide production causes the activation of 5 major pathways involved in the pathogenesis of complications [18]. These being increased activation of the polyol pathway $[19,20]$ nonenzymatic glycation, and AGEs (advanced glycation end products) pathway [21], enhanced reactive oxygen production and actions [18], activation of the Diacylglycerol (DAG)-Protein Kinase (PK)C pathway [5] and altered plasma thiol level which is a known representative of oxidative stress in type 2 diabetics [22]. Furthermore direct inactivation of two critical anti atherosclerotic enzymes, endothelial nitric oxide synthase and prostacyclin synthase has also been observed [23]. Through these pathways, increased intracellular Reactive Oxygen Species (ROS) cause defective angiogenesis in response to ischemia, activate a number of pro inflammatory pathways, and cause long-lasting epigenetic changes that drive persistent expression of pro inflammatory genes after glycemia is normalized (hyperglycemic memory). Eventually these proposed underlying and unifying multiple biochemical pathways lead to the hyperglycemia-induced intra- and extracellular changes and to alterations of signal transduction pathways, affecting gene expression and protein function, ultimately causing the cellular dysfunction and damage noticed in diabetes mellitus.

Thiamine has been shown to reduce these derangements through its effect on interconnecting pathways. High dose thiamine and Benfotiamine may counter the development of microvascular complications by activation of the reductive pentose phosphate pathway [24]. The mechanism appeared to be normalizing transketolase expression and activity in the non oxidative pentose pathway causing increased conversion of triosephosphates and fructose 6 phosphate to ribose-5-phosphate [25,26]. Bearing the above data in mind a pioneering clinical trial was conducted at Sheikh Zayed Hospital to study the effect of high dose thiamine therapy on its own levels, metabolic profile, microalbuminuria, plasminogen activation inhibitor 1 (PAI-1), oxidative stress plasma thiols and second messenger signaling protein kinase $\mathrm{C}$ profile in type 2 diabetic patients and to ascertain a therapeutic effect.

\section{Subjects and Methods}

\section{Chemicals, reagents, kits and instrumentation}

Purple topped and red topped tubes (for plasma and serum extraction respectively), $10 \mathrm{cc}$ syringes were purchased from Beckton Dickinson Company. Biochemical analyses kits for blood glucose, total cholesterol, triglycerides, LDL, total bilirubin, ALP, AST, AST, uric acid, serum/urine creatinine analysis, $\mathrm{CPK}$, blood urea nitrogen, was supplied by Dade Behring clinical chemistry system for dimension autoanalyser. The microalbuminuria kit, glycated hemoglobin estimation kit and Diastat autoanalyzer were supplied by Randox, while the spectrophotometer was provided by Shimadzu. Chemicals and kits were purchased from Sigma, Fluka, Merck and Elisa kits for Protein Kinase C (PKC 1), Plasminogen activation inhibitor1 (PAI-1) and Human soluble Vascular Adhesion Molecule-1 (Human sVCAM-1) determination were purchased from Stressgen Bioreagents, Technoclone and R\&D Quantikine respectively.

\section{Selection of patients and controls}

Over 100 type 2 diabetic patients with microalbuminuria and 50 normal healthy individuals (35-65 years old) were initially inducted at the Diabetes Clinic of Sheikh Zayed Hospital in a double blind randomized placebo controlled clinical trial applying stringent inclusion and exclusion criteria recommended by the American Diabetes Association for type 2 diabetes between October 1, 2006 and December 1, $2006[17,18]$.

The principal inclusion criteria for diabetic patients included type 2 diabetes defined by WHO (1999) criteria with age 36-65, duration ( 5 or more years), HbAlc $(\leq 1.5 \%)$, body mass index (19$40 \mathrm{~kg} / \mathrm{m}^{2}$ ), persistent microalbuminuria defined as albumin excretion between 30 and $300 \mu \mathrm{g} / \mathrm{min}$ in 3 overnight urine collections. The principal exclusion criteria were hepatitis, allergy to thiamine, taking thiamine supplements, severe excess alcohol consumption consume head and visceral organs of raw fish (source of thiaminase activity), pregnant women or breast feeding, childbearing women not taking contraceptive medicines or precautions, untreated or unsuccessfully treated psychiatric disease. Patients with persistent uncontrolled or untreated severe hypertension, planning to undertake surgery within the next 6 months, any abnormalities during recruitment screening with abnormal LFTs, RFTs and deranged hematological profile were also excluded. While the principal inclusion criteria for normal healthy controls included good health, age 35-65 years, matching for age and gender to the recruited diabetic patients $[17,18]$

\section{Randomization and treatment}

The patients and controls were divided on the basis of the randomization table into three groups A (normal healthy controls), B and $\mathrm{C}$ (diabetic type 2) having equal number of individuals in each group. Randomization was done by central office in sequentially numbered opaque and sealed envelopes. Participants, caregivers and those assessing the outcomes were blinded to this group assignment. Half of the inducted diabetic individuals were administered thiamine $3 \times 100 \mathrm{mg}$ tablets/day for three months, while the other half was treated with placebo. The 3 month treatment period was followed by two month washout period. Out of enrolled diabetic individuals and controls, 20 controls and 40 patients completed the 3 months thiamine/placebo administration and 2 month follow up period for this study $[17,18]$. Adverse and side effects of thiamine and placebo were determined by renal and liver function tests. Out of the 40 patients who completed the trial, in the placebo group, there were 7 male and 13 female patients of age $52.4 \pm 8.7 \mathrm{yrs}$ and BMI $28.3 \pm 4.4 \mathrm{~kg} / \mathrm{m}^{2}$. In the thiamine treatment group, there were 9 male and 11 female patients of age $52.7 \pm 8.4$ years and BMI $28.1 \pm 4.6 \mathrm{~kg} / \mathrm{m}^{2}$. At baseline and throughout the study, 9 patients in the thiamine treatment group and 3 in the placebo group were receiving insulin therapy $(p<0.05)$. There was no other significant difference in the proportions of patients receiving therapeutic agents in thiamine treatment and placebo groups.

\section{Ethical approval of the study}

Ethical approval for the study was taken from the Ethical/ Protocol/Synopsis Committee of FPGMI (Sheikh Zayed Federal Post Graduate Medical Institute, Lahore. Pakistan). The study was assigned the number as Eth/P 609/FPGMI 2006. It was internationally registered with the South Asian Clinical Trials Registry based in India as CTRI/2008/091/000112. Also registered with the World Health Organization's (WHO) International clinical trials registry platform search portal http://www.ctri.in/Clinicaltrials/ViewTrial.jsp? trialno= 203trialid=CTRI/2008/091/000112apps.who.int/trialsearch/trial.aspx? trialid=CTRI/2008/091/000112) $[17,18]$. 


\section{Methodologies}

Fasting Blood samples were obtained from the enrolled diabetic patients and normal healthy controls a baseline and subsequently after 3 month's therapy and 2 month washout. Plasma, serum, RBCS, mononuclear cells and RNA were removed from blood by centrifugation and specialized techniques. These were analyzed for biochemical parameters, transketolase, pyruvate dehydrogenase and alphaketoglutarate dehydrogenase activity and gene expression analyses. 24 hour urine collections were also made following an overnight fast and stored at between +2 to $+8^{\circ} \mathrm{C}$ prior to determination of microalbuminuria [17,18]. Routine biochemical parameters and specialized metabolic and renal profile parameters such as glycated hemoglobin and microalbuminuriaa were determined by standard referred protocols [27-37] and protocols provided by the kit manufacturers respectively $[38,39]$. The concentration of $\mathrm{HbA1C}$ in whole blood was measured by low pressure cation exchange chromatography in a Diastat automated analyzer [40].

Thiamine, TMP and TDP were determined by HPLC with flourimetric detection (precolumn derivitization to thiochromes) because of the increased specificity, sensitivity and reduced analysis time of this method [41]. Plasma thiamine concentration, urinary thiamine excretion and renal clearance of thiamine were also deduced [42]. The concentration of plasma thiols (mostly Cys-34 of serum albumin) was determined as originally described by Ellman [43] and modified by $\mathrm{Hu}$ [44]. Here, thiols interact with 5, 5'dithiobiss-(2nitrobenzoic acid) to form a highly colored anion with maximum peak at $412 \mathrm{~nm}$. ELISA based methods were used to determine PKC, PAI-1 antigen, levels in type 2 diabetic patients and controls.

\section{Power calculation and statistical analysis}

The primary endpoint was urinary albumin excretion. Group CV values and intervention effects of $30 \%$ were assumed, similar to previous studies. For power $=0.8$ and $\alpha<0.05$, patient group size was 17 . Patient groups of 20 were employed to allow for non-compliance to therapy. The data collected was analyzed using statistical package SPSS15 (Chicago IL, U.S.A), Significance of difference between the mean and median analytes of thiamine and placebo groups were determined by using students $t$ test and Mann Whitney $\mathrm{U}$ test respectively. While significance of difference from baseline to post therapy and post washout in mean and median analytes was determined by paired sample $T$ test and Wilcoxin signed rank test respectively $[17,18]$.

\section{Results}

The baseline demographic, physiologic and biochemical characteristics, thiamine and microalbuminuria levels of normal healthy controls and type 2 diabetic patients recruited for this study and randomized in the placebo and thiamine treatment arms are given in (Table 1) and elucidated below.

\section{Urinary albumin excretion profile}

Urinary albumin excretion in $\mathrm{mg} / 24 \mathrm{hrs}$ was significantly higher in the type 2 diabetics of both thiamine $(53.86 \pm 22.62) \mathrm{mg} / 24 \mathrm{hrs}$ and placebo groups $(55.74 \pm 23.71) \mathrm{mg} / 24 \mathrm{hrs}$ as compared to controls $(7.968$ $\pm 5.07) \mathrm{mg} / 24 \mathrm{hrs}$. This reflected the presence of microalbuminuria (30-300 $\mathrm{mg} / 24 \mathrm{hrs})$ in the patients as compared to controls which was an inclusion criteria requirement (Table 1) $[17,18]$.

\section{Thiamine and metabolic profile}

The median plasma thiamine concentration of thiamine and placebo treated diabetic patients was $10.6(0.8-84.5) \mathrm{nmol} / \mathrm{l}$ and 7.1 (1.131.3) $\mathrm{nmol} / \mathrm{l}$ respectively (Table 1 ), which was markedly lower than the normal range of normal healthy human subjects $(44.6-93.7 \mathrm{nmol} / \mathrm{l})$ The median urinary thiamine excretion was $1.63(0.45-7.66) \mu \mathrm{mol} / 24$ $\mathrm{h}$ and thiamine clearance was $112(8-819) \mathrm{ml} / \mathrm{min}$ in the thiamine group. While in the placebo group the median thiamine excretion was $1.53(0.67-4.46) \mu \mathrm{mol} / 24 \mathrm{~h}$ and thiamine clearance was 189 (26995) $\mathrm{ml} / \mathrm{min}$. At baseline, a negative correlation of plasma thiamine concentration with thiamine clearance and a positive correlation of urinary thiamine excretion and thiamine clearance were observed $[17,18]$. There was no significant difference in the plasma thiamine concentration, urinary thiamine excretion and renal clearance of thiamine between the patients as shown in table $1[17,18]$.

The metabolic profile of normal healthy controls showed a mean fasting plasma glucose concentration at $89.3 \pm 19.64 \mathrm{mg} \mathrm{dl}$, glycated hemoglobin $5.6 \pm 0.39 \%$, lipid profile LDL $115.89 \pm 29.37 \mathrm{mg} / \mathrm{dl}$, VLDL $26.62 \pm 20.22 \mathrm{mg} / \mathrm{dl}$, HDL44 $15 \pm 120.05 \mathrm{mg} / \mathrm{dl}$, cholesterol $188.3 \pm$ $33.93 \mathrm{mg} / \mathrm{dl}$ and triglycerides $133.10 \pm 108.45 \mathrm{mg} / \mathrm{dl}$ (Table 1). While Type 2 thiamine allocated diabetics registered mean fasting plasma glucose concentration at $181.8 \pm 57.6 \mathrm{mg} / \mathrm{dl}$, mean glycated $\mathrm{HbAlc}$ $9.2 \pm 1.3(\%)$, LDL $10634 \pm 47.14 \mathrm{mg} / \mathrm{dl}$, VLDL $46.33 \pm 31.79 \mathrm{mg} /$ dl, HDL $49.88 \pm 13.53 \mathrm{mg} / \mathrm{dl}$, cholesterol $203.40 \pm 50.27 \mathrm{mg} / \mathrm{dl}$ and triglycerides $240.10 \pm 168.55 \mathrm{mg} / \mathrm{dl}$ (Table 1). Those randomized to the placebo arm had fasting plasma glucose concentration $171 \pm 55.8 \mathrm{mg} /$ $\mathrm{dl}$, mean glycated haemoglobin $8.82 \pm 1.8 \%$, LDL $106.34 \pm 35.96 \mathrm{mg} / \mathrm{dl}$, $185.22 \pm 40.981 \mathrm{mg} / \mathrm{dl}$, VLDL $42.67 \pm 7.10 \mathrm{mg} / \mathrm{dl}$, HDL $47.95 \pm 10.44$, cholesterol, $185.22 \pm 40.9 \mathrm{mg} / \mathrm{dl}$ and triglycerides $156.15 \pm 81.74 \mathrm{mg} /$ dl (Table 1).

Significant difference was found between plasma glucose and triglycerides of healthy controls and thiamine group diabetics $(p<0.001)$ and also between the triglycerides levels of the normal controls and the placebo group ( $\mathrm{p}$ value $<0.01$ ). Other significant baseline differences were found between glycated hemoglobin and VLDL levels of normal controls and both thiamine and placebo diabetics $(\mathrm{p}<0.01)$ and between the serum HDL levels of the 3 groups $(\mathrm{p}<0.05)$. Total cholesterol levels were significantly raised in the thiamine group only, whereas a nonsignificant difference was found between LDL levels of normal controls and both thiamine and placebo group (Table 1).

\section{Hemostasis, cellular signalling mediator and oxidative stress profile}

Significantly lower Plasminogen activation inhibitor PAI1 values were found at baseline in normal controls $(3.09 \pm 1.83 \mathrm{ng} /$ $\mathrm{ml})$ as compared to thiamine group $(5.40 \pm 1.01 \mathrm{ng} / \mathrm{ml})$ and placebo group levels of $(5.91 \pm 1.68 \mathrm{ng} / \mathrm{ml})(\mathrm{p}<0.001)$ (Table 1$)$. Significantly higher mean protein kinase $c$ levels were present at baseline in both thiamine $(68.00 \pm 15.30 \mathrm{pg} / \mu \mathrm{g})$ and placebo groups $(76.65 \pm 56.22 \mathrm{pg} /$ $\mu \mathrm{g})$ in comparison to normal control values of $20.57 \pm 7.7 \mathrm{pg} / \mu \mathrm{g}(\mathrm{p}$ : 0.008) (Table 1). Significant difference was found at baseline between mean values of plasma thiols in healthy controls and thiamine and placebo allocated type 2 diabetics (Table 1) Mean. Plasma thiols concentration was $5.13 \pm 0.85 \mathrm{nmol} / \mu \mathrm{l}$ in healthy controls and $3.91 \pm$ $0.72 \mathrm{nmol} / \mu \mathrm{l}$ in the thiamine group. While in the placebo group the plasma thiol levels were $4.15 \pm 0.86 \mathrm{nmol} / \mu \mathrm{l}$. Detailed profiles of all parameters were maintained for the enrolled type 2 micro-albuminuric patientsthroughout the trial duration, after 3 months post therapy and 2 month washout period and some of the data has already been published in our paper. These investigations revealed certain beneficial effects of high dose $300 \mathrm{mg} /$ day thiamine therapy and absence of adverse effects $[17,18]$. 
Citation: Alam SS, Riaz S, Waheed Akhtar M (2012) Effect of High Dose Thiamine Therapy on Risk Factors in Type 2 Diabetics. J Diabetes Metab 3: 233. doi:10.4172/2155-6156.1000233

Page 4 of 9

\section{Effect of high dose thiamine therapy on microalbuminuria}

The effect of high dose thiamine therapy or placebo on urinary albumin excretion was a noticeable endpoint of this study. At baseline the thiamine group median MAU values were 43.7 (33.0-120.9 mg/24 hrs) versus 50.9 (32.9-121.7 mg/24 hrs) of the placebo group. After the treatment period, patients receiving thiamine therapy had decreased median urinary albumin excretion, with respect to patients receiving the placebo (30.1 (12.0-38.2) versus 35.5 (6.4-82) mg/24 hrs; $\mathrm{P}<0.01$ ). At washout the MAU values for thiamine versus placebo group were (20.9 (70-35.00 mg/24 hrs) versus (30.0 (3.5-80.4 mg/24 hrs). Urinary albumin excretion was decreased significantly with respect to baseline in the patients treated for 3 months with thiamine $(17.7 \mathrm{mg} / 24 \mathrm{hrs}$; $\mathrm{P}<0.001)$ but not in patients treated with placebo. The decrease in MAU was maintained after the washout period when the decrease in the urinary albumin in the patients treated with placebo also became significant (Table 2) (Figure 1). However importantly a noticeable progressively declining pattern of urinary albumin excretion over time was observed in patients treated with thiamine which was 4 -fold more as compared to those who had been administered placebo $t$ ( 5.62 versus $1.52 \mathrm{mg} / 24 \mathrm{hrs}$ ) (Table 2) (Figure 1).

No significant effect on daily glycaemic control was observed with thiamine therapy during the treatment period. However after the washout period, fasting plasma glucose $144 \mathrm{mg} / \mathrm{dl}$ was found significantly decreased in thiamine group by $37.8 \mathrm{mg} / \mathrm{dl}$ ) with respect to baseline levels $(\mathrm{p}<0.05)$, while the placebo treatment group also showed a similar significant decrease of $33.58 \mathrm{mg} / \mathrm{dl}$ by washout $(\mathrm{p}$ value $<0.05)$ (Table 2). However long term glycemic regulation showed prominent improvement as HbAlc levels was significantly decreased by $1.4 \%$ from $9.2 \%$ at baseline to post therapy level of $9.0 \%$ and a washout level of $7.8 \%$ in the thiamine administered group ( $p$ value $<0.01$ ). No such significant decrease occurred in the placebo group where the $\mathrm{HbA1c}$ levels remained relatively steady between $8.8 \%$ at baseline, $8.5 \%$ post therapy and $8.4 \%$ during washout (Table 2).

\section{Plasma and urinary thiamine profile}

The plasma thiamine levels of the thiamine treated group rose significantly higher, almost tenfold from (median value) 10.6 (0.884.5) nmoles/l) at baseline to median value 98.2 (2.6-294.5) nmoles/l after 3 months treatment $(\mathrm{p}<0.01)[17,18]$. During washout these levels returned to $10.9(3.6-22.7 \mathrm{nmoles} / \mathrm{l})$ in the thiamine group which were significantly lower than during therapy $(p<0.001)$. The plasma thiamine levels in the placebo group remained significantly unaltered from baseline to end of therapy at (median value) $7.1 \mathrm{nmoles} / \mathrm{l}$ to 9.1 (4.2-16.3 nmoles/l) at 2 months washout (Table 2).

The urinary thiamine values of the thiamine treated group recorded a 29 fold significant increase from baseline (median value) $1.63(0.45-7.66 \mu$ moles/24 hrs) to 47.69 (0.40-182.79 $\mu$ moles/24 hrs) (median value) post therapy, from its own baseline $(\mathrm{p}<0.001)$ and

\begin{tabular}{|c|c|c|c|c|}
\hline S. No. & Variables*(Normal range) & Control Group & Thiamine allocated group & Placebo allocated group \\
\hline 1 & Age (years) & $49.13 \pm 8.79$ & $52.7 \pm 8.4$ & $52.40 \pm 8.7$ \\
\hline 2 & Sex & 11F,9M & $9 \mathrm{M}, 11 \mathrm{~F}$ & $7 \mathrm{M}, 13 \mathrm{~F}$ \\
\hline 3 & Height (m) & $1.59 \pm 0.7$ & $1.57 \pm 28.4$ & $1.58 \pm 52.9$ \\
\hline 4 & Weight (kg) & $68.56 \pm 16.99$ & $69.12 \pm 18.4$ & $71.27 \pm 22.7$ \\
\hline 5 & Diastolic BP $(\mathrm{mmHg})(<90)$ & $78 \pm 7$ & $87 \pm 8$ & $84 \pm 6$ \\
\hline 6 & Systolic $\mathrm{BP}(\mathrm{mmHg})(<140)$ & $118.2 \pm 9$ & $126 \pm 14$ & $131 \pm 10$ \\
\hline 7 & $\mathrm{BMI}(\mathrm{kg} / \mathrm{m} 2)(19-40)$ & $26.93 \pm 4.92$ & $28.1 \pm 4.6$ & $28.3 \pm 4.4$ \\
\hline 8 & FBS (mg/dl) $(<100)$ & $89.3 \pm 19.64$ & 181.8. $\pm 57.6^{c}$ & $171 \pm 55.8^{c}$ \\
\hline 9 & $\mathrm{HbA1c}(\%)(4.3-6.1)$ & $5.6 \pm 0.39$ & $9.2 \pm 1.3^{\mathrm{B}}$ & $8.82 \pm .1 .8^{\mathrm{B}}$ \\
\hline 10 & LDL (mg/dl)(70-130) & $115.89 \pm 29.37$ & $106.34 \pm 47.14$ & $106.34 \pm 35.96$ \\
\hline 11 & VLDL (mg/dl)(5-41) & $26.62 \pm 20.22$ & $46.33 \pm 31.79^{A}$ & $42.67 \pm 7.103^{A}$ \\
\hline 12 & $\mathrm{HDL}(\mathrm{mg} / \mathrm{dl})(35-60)$ & $44.15 \pm 120.05$ & $49.88 \pm 13.53^{\mathrm{A}}$ & $47.95 \pm 10.44^{\mathrm{A}}$ \\
\hline 13 & Cholesterol (mg/dl)(0-200) & $187.21 \pm 33.19$ & $203.40 \pm 50.27^{B}$ & $185.22 \pm 40.98$ \\
\hline 14 & TG (mg/dl)(30-150) & $133.10 \pm 108.45$ & $240.10 \pm 168.55^{c}$ & $156.15 \pm 81.740^{\mathrm{B}}$ \\
\hline 15 & Urine Albumin $(\mathrm{mg} / 24 \mathrm{~h})(0-30)$ & $7.968 \pm 5.07$ & $53.86 \pm 22.62^{c}$ & $55.74 \pm 23.71^{c}$ \\
\hline 16 & GFR (ml/min)(90-120) & $102.43 \pm 38.60$ & $85 \pm 19$ & $93 \pm 23$ \\
\hline 17 & Uric acid mg/dl(3.5-8.5) & $4.65 \pm 1.00$ & $4.65 \pm .10 .05$ & $3.99 \pm 1.09$ \\
\hline 18 & BUN mg/dl(7-21) & $10.45 \pm 2.350$ & $11.37 \pm 4.87$ & $12.25 \pm 2.245^{A}$ \\
\hline 19 & Serum Creatinine $\mathrm{mg} / \mathrm{dl}(0.8-1.4)$ & $0.820 \pm .132$ & $0.915 \pm 0.195$ & $0.84 \pm 0.24^{\mathrm{A}}$ \\
\hline 20 & Urine Creatininemg/dl(30-125) & $47.63 \pm 36.117$ & $42.39 \pm 25.635^{\mathrm{A}}$ & $42.67 \pm 31.76^{A}$ \\
\hline 21 & Bilirubin (mg/dl ) (0.1-1) & $0.59 \pm 0.403$ & $0.55 \pm .244$ & $0.52 \pm 0.279$ \\
\hline 22 & $\operatorname{ALP}(\mathrm{U} / \mathrm{L})(20-160)$ & $95.90 \pm 34.20$ & $103.30 \pm 33.4847^{A}$ & $88.20 \pm 29.848^{A}$ \\
\hline 23 & AST (U/L) (15-37) & $29.15 \pm 11.123$ & $22.60 \pm 9.703$ & $21.65 \pm 7.700^{A}$ \\
\hline 24 & ALT (U/L) (30-65) & $40.90 \pm 12.191$ & $360.05 \pm 10.49^{A}$ & $36.10 \pm 10.40$ \\
\hline 25 & CK(U/L)( M:38-174,F:96-140) & $108.50 \pm 70.04$ & $81.85 \pm 52.30$ & $69.95 \pm 55.35$ \\
\hline 26 & Plasma thiamine $(\mathrm{nmol} / \mathrm{L})$ & $44.63-93.7$ & $10.6(0.8-84.5)^{\mathrm{C}}$ & $7.1(1.1-31.3)^{C}$ \\
\hline 27 & Urine thiamine $(\mu \mathrm{mol} / 24 \mathrm{~h})$ & & $1.63(0.45-7.66)^{\mathrm{C}}$ & $1.53(0.67-4.46)^{\mathrm{C}}$ \\
\hline 28 & PAl1(ng/ml) (7-43) & $3.094 \pm 1.83$ & $5.40 \pm 1.01 \mathrm{C}$ & $5.91 \pm 1.68 \mathrm{c}$ \\
\hline 29 & Protein kinase $\mathrm{C}(\mathrm{pg} / \mathrm{ug})$ & $20.57 \pm 7.7$ & $68.00 \pm 15.30^{c}$ & $76.65 \pm 56.22^{c}$ \\
\hline 30 & Plasma thiols $(\mathrm{nmol} / \mu \mathrm{l})$ & $5.13 \pm 0.85$ & $3.91 \pm .72^{\mathrm{B}}$ & $4.15 \pm 0.86^{\mathrm{B}}$ \\
\hline
\end{tabular}

Data are mean \pm SD values. For comparison of control with diabetes samples, $\mathrm{A}_{p<0.05}$ (statistically significant), $\mathrm{B}_{p<0.01}$ (statistically significant), $\mathrm{C} p<0.001$ (statistically highly significant).Normal ranges given in brackets next to each variable

Table 1: Average values of the various physical and biochemical parameters of the different groups at baseline $(n=20)$ 
placebo group 3 months post treatment urinary thiamine excretion values of $1.71(0.15-9.73) \mu$ moles $/ 24 \mathrm{hrs}, \mathrm{p}<0.001)[17,18]$. During the washout period urinary thiamine median values reduced by 33.58 folds to $1.42(0.10-9.72 \mu$ moles $/ 24 \mathrm{hrs})$ in the thiamine group which was significantly lower than treatment values $\mathrm{p}<0.001[17,18]$. These values were still higher than the washout urinary thiamine median levels of 1.16 (0.00-5.44 $\mu$ moles $/ 24 \mathrm{hrs)}$ of the placebo treated patients (Table 2).

\section{Effect of high dose thiamine therapy on hemostasis, cellular} signalling mediator and oxidative stress profile

Mean Plasminogen Activation Inhibitor 1 levels of the thiamine group at baseline were $5.46 \pm 1.01 \mathrm{ng} / \mathrm{ml}$ which remained steady at 5.36 $\pm 0.99 \mathrm{ng} / \mathrm{ml}$ after therapy and $5.35 \pm 1.26 \mathrm{ng} / \mathrm{ml}$ after washout and did not register any significant change. However during the same period the placebo group registered a significant steady rise in its PA1 values from (baseline $5.91 \pm 1.68 \mathrm{ng} / \mathrm{ml}$ to post treatment $6.14 \pm 1.44 \mathrm{ng} / \mathrm{ml}$ and wash out $6.84 \pm 1.36 \mathrm{ng} / \mathrm{ml}$. Thus a significant difference $(0.006)$ was noted between the thiamine and placebo PAI-1 washout values (Table 3).

Protein kinase c levels after 3 month thiamine treatment were significantly reduced by $55 \%$ from mean baseline levels $60 \pm 15.30$ $\mathrm{pg} / \mathrm{ug}$ to $30.26 \pm 19.37 \mathrm{pg} / \mathrm{u}(-37.74 \mathrm{ng}: \mathrm{p}<0.05)$ which remained statistically significant even during the washout period $37.98 \pm 18.66$ $\mathrm{pg} / \mathrm{ug}$ as compared to placebo $(\mathrm{p}=0.003)$. Whereas in the placebo group baseline PKC levels were $76.65 \pm 56.22 \mathrm{pg} / \mathrm{ug}$ which showed no significant change during therapy $77.75 \pm 58.29 \mathrm{pg} / \mathrm{ug}$ and increased significantly by $(+20.92 \mathrm{pg} / \mathrm{ug})$ during the washout period to $98.67 \pm$ $76.48 \mathrm{pg} / \mathrm{ug}$ (p.020) (Table 3). Plasma thiols levels were $3.91 \pm 0.72$ $\mathrm{nmol} / \mu \mathrm{l}$ at baseline, $3.71 \pm 0.72 \mathrm{nmol} / \mu \mathrm{l}$ ( 3 months post therapy) and $3.69 \pm 0.64 \mathrm{nmol} / \mu \mathrm{l}$ (washout) in the thiamine treated group which did not significantly differ from the placebo group values of $4.15 \pm 0.86$ $\mathrm{nmol} / \mu \mathrm{l}$ (baseline), $4.01 \pm 0.89 \mathrm{nmol} / \mu \mathrm{l}$ (therapy) and $3.97 \pm 0.85 \mathrm{nmol} /$ $\mu$ l. Thus no significant impact of thiamine therapy on plasma thiols was noted in type 2 diabetics (Table 3 ).

\section{Discussion}

Diabetes mellitus and especially type 2 continues to impact the lives of millions of people worldwide and especially a substantial number of the Asian population due to environmental factors, food habits and low thiamine in the diet and lack of exercise [18]. The median plasma thiamine concentration in type 2 diabetics was $7.5 \mathrm{nmole} / \mathrm{l}$. This was 83.1892\% lower than the range determined for normal healthy controls (44.6-93.7 nM/l) [45]. When determined independently for the two groups the mean plasma concentration was $66.5-97.5 \%$ lower in the placebo group and $9.8-98.25 \%$ lowers in the thiamine group. These findings corroborated with previous ones $[46,47]$ as seen in a UK study plasma thiamine levels where type 2 diabetics had $(16.3 \mathrm{nmol} / \mathrm{l})$ $75 \%$ lower mean plasma thiamine levels than in normal volunteers $(64.1 \mathrm{nmol} / \mathrm{l})$ [45]. These differences could be possibly due to both dietary and genetic differences related to the handling of drugs by the cytochrome P450 of the liver $[48,49]$.

It was also evident in our study that following 3 months thiamine/ placebo therapy as median plasma and urinary thiamine levels both rose significantly, thiamine clearance amazingly did not increase to the same extent, in the thiamine treated patients while remaining high in the placebo group. On the basis of our own findings there appeared to be a significant loss of thiamine re-absorptive capacity in the proximal tubules of the kidney as thiamine reserves were depleted in the body at baseline. Another important point was that all diabetic patients in

\begin{tabular}{|c|c|c|c|c|c|c|}
\hline \multirow[t]{2}{*}{ Variable (Diabetic Range) } & \multicolumn{3}{|c|}{ Thiamine Treatment } & \multicolumn{3}{|c|}{ Placebo } \\
\hline & Baseline & Therapy & Washout & Baseline & Therapy & Washout \\
\hline Plasma thiamine $(\mathrm{nM} / \mathrm{l})$ & $10.6(0.8-84.5)$ & $98.2(2.6-294.5) c, f$ & $10.9(3.6-22.7) \mathrm{i}$ & $7.1(1.1-31.3)$ & $7.1(2.4-16.6)$ & $9.1(4.2-16.3)$ \\
\hline Urinary thiamine $(\mu \mathrm{mol} / 24 \mathrm{~h})$ & $1.63(0.45-7.66)$ & $\begin{array}{l}47.69(0.40- \\
182.79) \mathrm{c}, \mathrm{f}\end{array}$ & $1.42(0.10-9.72) \mathrm{i}$ & $1.53(0.67-4.46)$ & $1.71(0.15-9.73)$ & $1.16(0.00-5.44)$ \\
\hline $\begin{array}{l}\text { Urinary albumin Excretion(mg/24 h)(30- } \\
300 \mathrm{MAU})\end{array}$ & $\begin{array}{l}43.7(33.0- \\
120.9)\end{array}$ & $\begin{array}{l}30.1(12.0- \\
38.2) b, f\end{array}$ & $\begin{array}{l}20.9(7.0- \\
35.0) f, h\end{array}$ & $50.9(33-122)$ & $35.5(6.4-82.0)$ & $30(3.5-80.4) f$ \\
\hline Thiamine clearance $(\mathrm{ml} / \mathrm{min})$ & $112(8-819)$ & 273(3-789)d & 92(18-237)h & $189(26-955)$ & $149(12-663)$ & $102(12-334) \mathrm{e}$ \\
\hline Plasma glucose (mg/dl)(>126) & $181.8 \pm 57.6$ & $181.8 \pm 70.2$ & $144 \pm 6.3 d$ & $177.58 \pm 55.8$ & $158.4 \pm 43.24$ & $144 \pm 55.8 d$ \\
\hline Glycated HbAic\% (>7 diabetes) & $9.2 \pm 1.3$ & $9.0 \pm 1.8$ & $7.8 \pm 1.6 \mathrm{e}, \mathrm{h}$ & $8.8 \pm 1.8$ & $8.5 \pm 1.7$ & $8.4 \pm 1.7$ \\
\hline Total cholesterol (mg/dl) 200-299)(high) & $203.40 \pm 50.27$ & $\begin{array}{l}188.32(100.15- \\
374.90)\end{array}$ & $\begin{array}{l}178.26 \\
(127.22-278.42\end{array}$ & $185.22 \pm 40.98$ & $171.30 \pm 64.19$ & $215.39 \pm 76.7 \mathrm{~h}$ \\
\hline $\begin{array}{l}\text { LDL-cholesterol (mg/dl) } \\
\text { (130-159(borderline high) }\end{array}$ & $106.34 \pm 47.14$ & $98.996 \pm 66.12$ & $93.19 \pm 32.09 a$ & $106.34 \pm 35.96$ & $92.05 \pm 460.01$ & $123.35 \pm 47.95 \mathrm{~g}$ \\
\hline VLDL(mg/dl)( 40-100(high) & $46.330 \pm 31.792$ & $55.62 \pm 36.46 b$ & $48.260 \pm 30.62$ & $31.30 \pm 16.339$ & $36.425 \pm 17.24 d$ & $38.760 \pm 13.9 e$ \\
\hline $\begin{array}{l}\mathrm{HDL} \text {-cholesterol }(\mathrm{mg} / \mathrm{dl})(\mathrm{F}<50, \mathrm{M}<40) \\
\text { increased risk of coronary artery disease }\end{array}$ & $49.88 \pm 13.53$ & $41.76 \pm 14.30 \mathrm{~d}$ & $44.47 \pm 9.28$ & $47.95 \pm 10.44$ & $37.50 \pm 8.89 f$ & $52.97 \pm 21.65 h$ \\
\hline Triacylglycerol (mg/dl) (200-499 high), & $\begin{array}{l}198.47(53.4- \\
739.59)\end{array}$ & $\begin{array}{l}202.03(81.66- \\
620.73)\end{array}$ & $\begin{array}{l}231.4(79.21- \\
736.03)\end{array}$ & $\begin{array}{l}134.39(72.98- \\
377.3)\end{array}$ & $\begin{array}{l}159.31(56.07- \\
357.78) d\end{array}$ & $\begin{array}{l}175.33(96.12- \\
396.94) d\end{array}$ \\
\hline BILIRUBIN(0.1-1mg/dl) & $0.550 \pm 0.244$ & $0.470 \pm 0.194 \mathrm{e}$ & $0.503 \pm 0.24$ & $0.514 \pm 0.283$ & $0.382 \pm 0.185 \mathrm{~g}$ & \\
\hline ALP(U/L)20-160 & $103.30 \pm 33.48$ & $102.85 \pm 33.25$ & $91.10 \pm 24.83$ & $88.20 \pm 29.84$ & $80.65 \pm 44.75$ & $84.1 \pm 34.15$ \\
\hline ALT(U/L)30-65 & $360.05 \pm 10.49$ & $31.15 \pm 10.36$ & $32.10 \pm 10.59$ & $36.10 \pm 10.40$ & $31.85 \pm 11.41$ & $36.20 \pm 15.81$ \\
\hline AST(U/L)15-37 & $22.60 \pm 9.70$ & $19.00 \pm 7.21$ & $22.15 \pm 9.36$ & $21.65 \pm 7.70$ & $15.95 \pm 8.80 \mathrm{~d}$ & $20.55 \pm 5.68$ \\
\hline
\end{tabular}

Table 2: The Thiamine, metabolic and liver function profile before and after three month thiamine treatment and after two month washout period. 


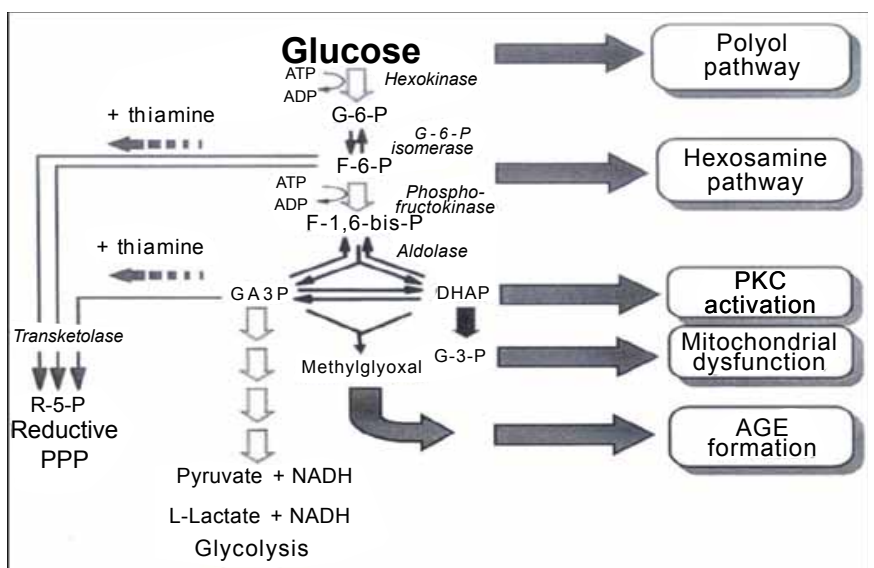

Figure 1: Proposed mechanism of high dose thiamine therapy in countering deleterious activation of the polyol, hexosamine, PKC, mitochondrial dysfunction \& AGE formation (Adapted from PJ Thornalley06).

this study despite having an adequate dietary intake of thiamine as reflected by urinary excretion of thiamine $>0.20 \mu \mathrm{mol} / 24 \mathrm{hrs}[17,18,50]$ had low levels of plasma thiamine. These could be therefore, the result of increased washout rather than inadequate ingestion of vitamin B1.

An explanation for the decrease in thiamine re-absorption by the kidney upon encountering thiamine depletion could lie in the transporter protein and in the expression of the genes encoding them. Physiologically, thiamine re-uptake occurs in the proximal convoluted tubules by THTR 1 and THTR 2 transporters via a sodium independent proton antiport mechanism regulated by $\mathrm{CA} /$ calmodulin [51]. Evidence suggests the expression of the genes encoding these transporters to be regulated by SP1 promoterelements [52,53]. SP1 signaling in the tubular epithelium is impaired in hyperglycemia associated with diabetes by increased O-glycosylation of the SP1 via enhanced hexosamine pathway activity [54]. Thus re-uptake of thiamine could have reduced by the hexosamine linked pathway or further due todicarbonyl glycation of thiamine transporters [55] or even by acidification of tubular lumen [56]. The improvement in thiamine reuptake observed with the 3 month thiamine versus placebo therapy and its return to baseline after 2 months washout could also have been due to the increased activity of thiamine dependant enzymes $\mathrm{PDH}, \mathrm{OGDH}$ and TKT activity within the tubular epithelial cells and improved cellular metabolism and functioning of these cells reflected as decreased thiamine clearance versus plasma levels. However, eventually at the end of 2 months washout plasma thiamine levels had declined but intracellular enzyme activity was maintained specially in the mononuclear cells and less so in the renal tubular cells which are reported to suffer quick depletion and have low TK expression [56].

The patients enrolled in this study exhibited poor glycemic control with a significantly raised mean fasting blood sugar levels $103 \%$ and 98.76\% $(\mathrm{p}<0.001)$ in both the thiamine and placebo as compared to normal controls at baseline and correspondingly elevated glycated hemoglobin levels as well. This was comparable to a previous study in our population [57]. Mean glycated HbAlc levels in 24 type 2 diabetics with microalbuminuria in the UK were $8.5 \%$ and also comparable to our baseline levels.

Thiamine therapy at $300 \mathrm{mg} /$ day for 3 months had no impact on fasting blood initially but during 2 months washout period there were comparable decreases in fasting blood sugar in both groups which was $20.83 \%$ in the thiamine group and $18.90 \%$ in the placebo group $(\mathrm{p}<0.05)$. This finding was different from that reported by the European Journal of Nutrition, in a study involving thiamine supplementation in a randomized double blind placebo controlled trial in 24 drug naïve type 2 diabetics. At the end of a month, the thiamine treated group showed significant decreases $(6.7 \mathrm{mmol} / \mathrm{l})$ in blood sugar levels $[58,59]$. Our results differed as both thiamine and placebo groups were equally balanced for hypoglycemic drugs other than thiamine during the trial and the reduction in blood sugar levels in both groups at washout reflected the effect of these agents and an absence of any thiamine effect on this parameter.

However fasting plasma blood sugar level is only representative of that day's fasting glucose record and is not representative of the overall glycemic control. Glycated hemoglobin is thus more representatives the holistic glycemic scenario. Interestingly during this trial glycated hemoglobin levels in the thiamine treated type 2 diabetics registered a significant percentage decrease of $15.2 \%(\mathrm{p}<0.001)$ from the start of therapy to the washout period, while no significant change was recorded in the placebo group. $\mathrm{HbAlc}$ level is generally considered to be proportional to the average blood glucose concentration over the previous 8-12 weeks [60]. Some researchers state that the major portion of its value is related to a rather short period of two to four weeks [61]. Therefore the reason for the gradual decrease in hemoglobin in the thiamine treated group during the trial period was probably an actual first representation of reduced glycation of the previous 3 months and the significant decrease noticed during the washout period was actually a most apparent manifestation of decrease in $\mathrm{HbAlc}$ during the last month of therapy.

In this study, the baseline median values of microalbuminuria were significantly raised in thiamine treated group $43.79 \mathrm{mg} / 24 \mathrm{hrs}$ ( 6.7 fold $)$ in the thiamine group and $50.91 \mathrm{mg} / 24 \mathrm{hrs}$ ( 7 fold) in the placebo group as compared to normal controls $(\mathrm{p}<0.001)$. The UK microalbuminuric patient's median $46 \mathrm{mg} / 24 \mathrm{hrs}$ [45] was comparable to our study. Whereas in the Dutch benfotiamine trial the median baseline values of microalbuminuria were $90 \mathrm{mg} / 24 \mathrm{hrs}$ ) in the benfotiamine group and (97 mg/24 hrs) in the placebo group [49] were approximately 2 times higher than in our study.

We found that high dose thiamine therapy $(3 \times 100 \mathrm{mg}$ per day $)$ significantly decreased urinary excretion of albumin in type 2 diabetic patients with microalbuminuriaa from baseline values after 1-3 months therapy $(p<0.001)$. After therapy for 3 months, regression of microalbuminuria to normal urinary albumin had occurred in $35 \%$ of the patients. This decrease in urinary albumin excretion continued during the washout period as ongoing benefit from thiamine supplementation in the previous 3 months. No significant decrease in Urinary Albumin Excretion (UAE) was observed in those who had received placebo $[17,18]$. Prolonged regression of micro albuminuria into the washout period could be that even though the half-life of thiamine was about 2 days being relatively short [62], its biological half-life (9-18 days) was much greater [63]. So even though the plasma concentration and urinary excretion of thiamine in the thiamine treatment arm returned to baseline after 2 months washout period, it was likely that increased tissue levels of TPP, activities of thiamine dependant enzymes and related pharmacological responses remained above baseline for at least one biological half life of thiamine in the washout period of the patients in the thiamine treatment group [45].

Oxidative stress plays a crucial role in atherogenesis in diabetes [18]. Measurements of plasma thiols (a marker for oxidative stress) at baseline revealed significant differences between baseline levels of 


\begin{tabular}{|c|c|c|c|c|c|c|}
\hline \multirow[t]{2}{*}{ Variable (Diabetic Range) } & \multicolumn{3}{|c|}{ Thiamine Treatment } & \multicolumn{3}{|c|}{ Placebo } \\
\hline & Baseline & Therapy & Washout & Baseline & Therapy & Washout \\
\hline Creatine Kinase U/L(M:38-174; F:96-140) & $81.85 \pm 52.30$ & $86.20 \pm 62.04 \mathrm{~g}$ & $141.90 \pm 114.20 \mathrm{id}$ & $69.95 \pm 55.35$ & $58.30 \pm 37.19 \mathrm{~g}$ & $75.85 \pm 42.78$ \\
\hline Uric acid mg/dl(3.5-8.5) & $4.65 \pm 10.05$ & $3.75 \pm 1.49 \mathrm{~h}$ & $4.82 \pm 1.47 e$ & $3.99 \pm 1.09$ & $40.03 \pm 1.70$ & $4.45 \pm 0.93$ \\
\hline Blood Urea Nitrogen mg/dl(7-21) & $11.70 \pm 4.87$ & $12.45 \pm 5.24$ & $140.05 \pm 4.76 \mathrm{~d}$ & $12.25 \pm 2.24$ & $9.9 \pm 4.59 \mathrm{~d}, \mathrm{~g}$ & $14.8 \pm 5.92 d$ \\
\hline GFR (ml/min) (<60 chronic renal disease) & $85 \pm 19$ & $90 \pm 30$ & $77 \pm 20$ & $93 \pm 23$ & $97 \pm 18$ & $\begin{array}{l}87 \pm 21 P^{\prime}<0.05 \\
P^{\prime \prime}<0.01\end{array}$ \\
\hline Serum creatinine mg/dl) $(0.8-1.4)$ & $0.915 \pm 0.195$ & $0.84 \pm 0.28 \mathrm{~g}$ & $0.95 \pm 0.25$ & $0.84 \pm 0.24$ & $0.77 \pm 0.20 \mathrm{i}$ & $0.94 \pm 0.21$ \\
\hline Urine creatinine (mg/dl) $(30-125)$ & $42.4 \pm 25.63$ & $45.86 \pm 31.14$ & $43.73 \pm 37.37$ & $42.65 \pm 31.76$ & $59.1 \pm 41.37 d$ & $66.59 \pm 34.78 \mathrm{e}$ \\
\hline Diastolic BP $(\mathrm{mmHg})(<90)$ & $87 \pm 7$ & $85 \pm 9$ & $87 \pm 7$ & $84 \pm 6$ & $84 \pm 8$ & $83 \pm 7$ \\
\hline Systolic BP $(\mathrm{mmHg})(<140)$ & $126 \pm 14$ & $133 \pm 20$ & $135 \pm 14 P^{\prime}<0.05$ & $131 \pm 10$ & $130 \pm 17$ & $130 \pm 13$ \\
\hline
\end{tabular}

Table 3: Endothelial Dysfunction, Hemostasis, Oxidative Stress and Cellular Signalling Mediator Profile before and after three month thiamine treatment and after two month washout period.

\begin{tabular}{|c|c|c|c|c|c|c|}
\hline \multirow[t]{2}{*}{ Variable (Diabetic Range) } & \multicolumn{3}{|c|}{ Thiamine Treatment } & \multicolumn{3}{|c|}{ Placebo } \\
\hline & Baseline & Therapy & Washout & Baseline & Therapy & Washout \\
\hline S VCAM1 (ng/ml) & $588 \pm 267$ & $554 \pm 224$ & $\begin{array}{l}481 \pm 192 d, g \\
P^{\prime}<0.05 \\
P^{\prime \prime}<0.05\end{array}$ & $648 \pm 255$ & $608 \pm 178$ & $600 \pm 232$ \\
\hline $\mathrm{VWF}(\mathrm{U} / \mathrm{ml})$ & $\begin{array}{l}0.67(0.07- \\
5.18)\end{array}$ & $0.48(0.01-2.95)$ & $0.51(0.071-1.97)$ & $0.48(0.01-4.35)$ & $0.48(0.01-4.41)$ & $0.59(0.01-1.61)$ \\
\hline
\end{tabular}

Table 4: Renal function profile and physiological data before and after three month thiamine treatment and after two month washout period.

thiamine treated $-23 \%(\mathrm{p}=0.001)$ and placebo group $-19.10 \%(\mathrm{p}=0.002)$ from normal controls with no significant change during treatment or washout stage in both thiamine and placebo groups. Thus thiamine displayed no effect on oxidative stress by reducing or enhancing the level of antioxidant plasma thiols in type 2 diabetics in this study. A significant decrease in plasma thiols was also reported in diabetic patients on hemodialysis, which improved after a single dialysis session but remained low as compared to control participants and patients with DM [64]. The decreased thiol concentration could be the result of enhanced oxidative stress in diabetic patients on hemodialysis [65].

Protein kinase $\mathrm{C}$ is a phospholipid and calcium sensitive protein kinase. It can regulate a number of cellular events by activating MAP kinases which depending on cell type including extracellular signal related kinases ERKS, cJun N terminal kinases JNKs and p38 MAPKs [66]. In diabetes, increased hyperglycemia induced superoxide causes glycolytic intermediates to be shunted into the major pathways of hyperglycemic damage. These intermediates activate the intracellular AGE formation, the hexosamine pathway and protein kinase C [67]. In this study protein kinase $\mathrm{C}$ levels at baseline were significantly 3.4 fold higher $(p=0.008)$ in thiamine treated group and 3.72 fold higher $(\mathrm{p}=0.000)$ in the placebo treated group versus normal controls. While during treatment level of PKC in monocytes of thiamine treated diabetics was reduced significantly by $55 \%(\mathrm{p}=0.027)$ which was not sustained during the washout period. Placebo treatment resulted in significant increase in their protein kinase C levels of $26.09 \%(20.92 \mathrm{pg} /$ $\mu \mathrm{g} ; \mathrm{p}<0.05)$ which persisted during the washout period.

Statistical analysis of the pkc levels between the two groups at 3 months post treatment showed this change to be even more significant during treatment $(\mathrm{p}=0.002)$ and $(\mathrm{p}=0.003)$ during washout. No comparative data from another trial was available as protein kinase $\mathrm{C}$ activity was not measured in circulating monocytes in both benfotiamine trial on type 2 diabetics [49] and the benfotiamine and alpha lipoic acid trial in type 1 diabetics [68]. Thiamine's therapeutic benefit of the reversal of hyperglycemia induced protein kinase $\mathrm{C}$ expression and decreased extracellular matrix deposition during therapy with prolongation of this effect have been reported [69].

Plasminogen activation inhibitor type 1 (PAI-1) is another nontraditional risk factor for cardiovascular disease in diabetes [3] This is part of the endogenous fibrinolytic system and its increase signals impaired fibrinolysis and prothrombotic state [10]. At baseline, measurements revealed $74 \%$ and $91 \%$ significantly higher levels of PAI1 in thiamine and placebo treated patients respectively as compared to normal controls $(\mathrm{p}=0.000)$.

In this study an increase of $15 \%$ of PAI-1was noted from baseline to washout in the placebo group was significant in comparison to the thiamine group at washout $(\mathrm{p}=0.005)$. There are reports of drugs such as ACE inhibitors significantly decreasing PAI-1 without altering tissue plasminogen activator and no such effect being seen with ARB [70] Better glycemic control in the thiamine group displayed as reduced glycated hemoglobin levels in the 3 months treatment and washout period may have prevented increase in the PAI-1 as compared to the placebo group. Some studies have suggested that blood thrombogenicity is related to glycemic control and that improved diabetic control leads to a less thrombogenic state $[71,72]$.

\section{Conclusion}

In this internationally pioneering clinical trial thiamine levels of type 2 microalbuminuric diabetics as compared to normal controls were determined and the effect of high dose thiamine therapy on a number of risk factors associated with type 2 diabetes mellitus were studied. These results were encouraging and suggest that the microvascular dysfunctions especially incipient diabetic nephropathy in type 2 diabetes occurs in the background of thiamine depletion leading to, impaired second messenger signaling mechanisms, endothelial malfunction and altered hemostasis through enhanced thrombogenicity which appear to respond well to thiamine therapy. Our study recommends daily oral thiamine administration of $300 \mathrm{mg} /$ day in type 2 diabetics to prevent depreciation of thiamine levels and maintenance of normal thiamine status in addition to conventional therapy of diabetes, as thiamine supplementation added a novel, viable, feasible, and secure dimension to the current diabetic pharmacotherapy as no hepatic, renal or other significant adverse effects were noted (Tables 2 and 4 ). 


\section{Acknowledgement}

The author is grateful to Higher Education Commission of Pakistan for funding the project.

\section{References}

1. World Health Organization (2003) Screening for Type 2 Diabetes. Report of a World Health Organization and International Diabetes Federation meeting

2. Centers for Diseases Control (2007) National Diabetes Fact sheet.

3. Centers for Disease Control and Prevention (2011) National Diabetes Fact Sheet, 2011. Atlanta, GA: Centers for Disease Control and Prevention, US Department of Health and Human Services.

4. Fonseca V, Desouza C, Asnani S, Jialal I (2004) Nontraditional risk factors for cardiovascular disease in diabetes. Endocr Rev 25: 153-175.

5. Geraldes P, King GL (2010) Activation of protein kinase C isoforms and its impact on diabetic complications. Circ Res 106: 1319-1331.

6. Koya D, King GL (2001) Kinase C activation and the development of diabetic complications. Nature 414: 813-820.

7. Ayo SH, Radnik R, Garoni JA, Troyer DA, Kreisberg JI (1991) High glucose increases diacylglycerol mass and activates protein kinase $C$ in mesangial cell cultures. Am J Physiol 261: F571-F577.

8. Ross R (1999) Atherosclerosis--an inflammatory disease. N Engl J Med 340 115-126.

9. Glass CK, Witztum JL (2001) Atherosclerosis. the road ahead. Cell 104: 503516.

10. Libby $P$ (2002) Inflammation in atherosclerosis. Nature 420: $868-874$.

11. Sobel BE (1999) Insulin resistance and thrombosis: a cardiologist's view. Am J Cardiol 84: 37J-41J.

12. Nordt TK, Bode $C$ (2000) Impaired endogenous fibrinolysis in diabetes mellitus: mechanisms and therapeutic approaches. Semin Thromb Hemost 26: 495-501.

13. Smith FB, Fowkes FG, Rumley A, Lee AJ, Lowe GD, et al. (2000) Tissue plasminogen activator and leucocyte elastase as predictors of cardiovascular events in subjects with angina pectoris: Edinburgh Artery Study. Eur Heart J 21: $1607-1613$

14. Thögersen AM, Jansson JH, Boman K, Nilsson TK, Weinehall L, et al. (1998) High plasminogen activator inhibitor and tissue plasminogen activator levels in plasma precede a first acute myocardial infarction in both men and women: evidence for the fibrinolytic system as an independent primary risk factor Circulation 98: 2241-2247.

15. Wieczorek I, Ludlam CA, Fox KA (1994) Tissue-type plasminogen activator and plasminogen activator inhibitor activities as predictors of adverse events in unstable angina. Am J Cardiol 74: 424-429.

16. Huber K, Christ G, Wojta J, Gulba D (2001) Plasminogen activator inhibitor type-1 in cardiovascular disease. Status report 2001. Thromb Res 103: S7S19

17. Carr ME (2001) Diabetes mellitus: a hypercoagulable state. J Diabetes Complications 15: 44-54.

18. Rabbani N, Alam SS, Riaz S, Larkin JR, Akhtar MW, et al. (2009) High-dose thiamine therapy for patients with type 2 diabetes and microalbuminuria: a randomised, double-blind placebo-controlled pilot study. Diabetologia 52: 208212

19. Brownlee M (2001) Biochemistry and molecular cell biology of diabetic complications. Nature 414: 813-820.

20. Giacco F, Brownlee M (2010) Oxidative stress and diabetic complications. Circ Res 107: 1058-1070.

21. Hink U, Li H, Mollnau H, Oelze M, Matheis E, et al. (2001) Mechanisms underlying endothelial dysfunction in diabetes mellitus. Circ Res 8: E14-E22.

22. Obrosova IG, Minchenko AG, Vasupuram R, White L, Abatan OI, et al. (2003) Aldose reductase inhibitor fidarestat prevents retinal oxidative stress and vascular endothelial growth factor overexpression in streptozotocin-diabetic rats. Diabetes 52: 864-871.

23. Wendt T, Harja E, Bucciarelli L, Qu W, Lu Y, et al. (2006) RAGE modulates vascular inflammation and atherosclerosis in a murine model of type 2 diabetes. Atherosclerosis 185: 70-77.

24. Telci A, Cakatay U, Salman S, Satman I, Sivas A (2000) Oxidative protein damage in early stage type 1 diabetic patients. Diabetes Res Clin Pract 50 213-223.

25. Wittenstein B, Klein M, Finckh B, Ullrich K, Kohlschütter A (2002) Plasma antioxidants in pediatric patients with glycogen storage disease, diabetes mellitus, and hypercholesterolemia. Free Radic Biol Med 33: 103-110.

26. Thornalley PJ, Jahan I, Ng R (2001) Suppression of the accumulation of triosephosphates and increased formation of methylglyoxal in human red blood cells during hyperglycaemia by thiamine in vitro. J Biochem 129: 543-549.

27. Beltramo E, Berrone E, Buttiglieri S, Porta M (2004) Thiamine and benfotiamine prevent increased apoptosis in endothelial cells and pericytes cultured in high glucose. Diabetes Metab Res Rev 20: 330-336.

28. Kunst A, Draeger B, Ziegenhorn, J (1983) UV-methods with hexokinase and glucose-6-phosphate dehydrogenase, Methods of Enzymatic analysis 6: 163172.

29. Rifai N, Russell Warnick G, Dominiczak MH (1997) Handbook of Lipoprotein Testing., AACC Pres: 115.

30. Rautela GS, Liedtke RJ (1978) Automated enzymic measurement of tota cholesterol in serum. Clin Chem 24: 108-114.

31. Gotto AM Jr (1988) Lipoprotein metabolism and the etiology of hyperlipidemia. Hosp Pract (Off Ed) 23: 4-13.

32. Assmann G (1979) HDL-cholesterol precipitant. Randox Labs. Ltd. CrumLin Co. Antrim, N. Ireland. Internist 20: 559-567.

33. Doumas BT, Kwok-Cheung PP, Perry BW, Jendrzejczak B, McComb RB, et al (1985) Candidate reference method for determination of total bilirubin in serum: development and validation. Clin Chem 31: 1779-1789.

34. Rej R (1977) Effect of incubation with $\mathrm{Mg}^{2+}$ on the measurement of alkaline phosphatase activity. Clin Chem 23: 1903-1911.

35. Bergmeyer HU, Scheibe P, Wahlefeld AW (1978) Optimization of methods for aspartate aminotransferase and alanine aminotransferase. Clin Chem 24: 58 73.

36. Saris NE (1978) Revised IFCC method for aspartate aminotransferase. Clin Chem 24: 720-721.

37. Tietz NW (1986) Textbook of Clinical Chemistry, W.B. Saunders Co. and Philadelphia, PA (techniques and procedures to minimize laboratory infections) 478-497 (specimen collection and storage recommendations) and 682-686 (general method).

38. Talke H, Schubert GE (1965) Enzymatic urea determination in the blood and serum in the warburg optical test. Klin Wochenschr 43: 174-175.

39. Garlick RL, Mazer JS, Higgins PJ, Bunn HF (1983) Characterization of glycosylated hemoglobins. Relevance to monitoring of diabetic control and analysis of other proteins. J Clin Invest 71: 1062-1072.

40. Horowitz MI (1982) The Glycoconjugates

41. Bakker SJ, Hoogeveen EK, Nijpels G, Kostense PJ, Dekker JM, et al. (1998) The association of dietary fibres with glucose tolerance is partly explained by concomitant intake of thiamine: the Hoorn Study. Diabetologia 41: 1168-1175.

42. Fayol V (1997) High-performance liquid chromatography determination of tota thiamin in biological and food products. Methods Enzymol 279: 57-66.

43. Ellman GL (1959) Tissue sulfhydryl groups. Arch Biochem Biophys 82: 70-77.

44. Hu ML (1994) Measurement of protein thiol groups and glutathione in plasma Methods Enzymol 233: 380-385.

45. Sander S, Hahn A, Stein J, Rehner G (1991) Comparative study on the high performance liquid chromatographic determination of thiamine and its phosphate esters with chloroethylamine as an internal standard usingprecolumnn and potassiumderivatizationn procedures J Chromatogr 558: 115-124

46. Thornalley PJ, Babaei-Jadidi R, Al Ali H, Rabbani N, Antonysunil A, et al. (2007) High prevalence of low plasma thiamine concentration in diabetes linked to a marker of vascular disease. Diabetologia 50: $2164-2170$.

47. Saito N, Kimura M, Kuchiba A, Itokawa Y (1987) Blood thiamine levels in outpatients with diabetes mellitus. J Nutr Sci Vitaminol (Tokyo) 33: 421-430. 
Citation: Alam SS, Riaz S, Waheed Akhtar M (2012) Effect of High Dose Thiamine Therapy on Risk Factors in Type 2 Diabetics. J Diabetes Metab 3: 233. doi:10.4172/2155-6156.1000233

Page 9 of 9

48. Valerio G, Franzese A, Poggi V, Patrini C, Laforenza U, et al. (1999) Lipophilic thiamine treatment in long-standing insulin-dependent diabetes mellitus. Acta Diabetol 36: 73-76

49. Katzung BG (2009) Basic and clinical pharmacology (12thedn), Pancreatic Hormones and Anti Diabetic Drugs. 2009: 711-734.

50. Alkhalaf A, Klooster A, van Oeveren W, Achenbach U, Kleefstra N, et al. (2010) A double-blind, randomized, placebo-controlled clinical trial on benfotiamine treatment in patients with diabetic nephropathy. Diabetes Care 33: 1598-1601.

51. Unnikrishnan RI, Rema M, Pradeepa R, Deepa M, Shanthirani CS, et al (2007) Prevalence and risk factors of diabetic nephropathy in an urban south Indian population: the Chennai Urban Rural Epidemiology Study (CURES 45). Diabetes Care 30: 2019-2024.

52. Ashokkumar B, Vaziri ND, Said HM (2006) Thiamin uptake by the humanderived renal epithelial (HEK-293) cells: cellular and molecular mechanisms. Am J Physiol Renal Physiol 291: F796-F805.

53. Tolner B, Singh A, Esaki T, Roy K, Sirotnak FM (1999) Transcription of the mouse RFC-1 gene encoding a folate transporter. Multiplicity and properties of promoters with minimum requirements for their basal activity. Gene 231:163172.

54. Reidling JC, Said HM (2003) In vitro and in vivo characterization of the minimal promoter region of the human thiamin transporter SLC19A2. Am J Physiol Cell Physiol 285: C633-C641.

55. Schleicher ED, Weigert C (2000) Role of the hexosamine biosynthetic pathway in diabetic nephropathy. Kidney Int Suppl 77: S13-S18.

56. Verri A, Laforenza U, Gastaldi G, Tosco M, Rindi G (2002) Molecula characteristics of small intestinal and renal brush border thiamin transporters in rats. Biochim Biophys Acta 1558: 187-197.

57. Nascimento-Gomes G, Zaladek Gil F, Mello-Aires M (1997) Alterations of the renal handling of $\mathrm{H}+$ in diabetic rats. Kidney Blood Press Res 20: 251-257.

58. Siddique SA, Akhtar MW, Cheema AM (2009) Role of glucose and insulin resistance in the development of non insulin dependent (type 2) diabetes mellitus and characteristic of associate health risk in Pakistan, PMRC.

59. Mooradian AD (2003) Cardiovascular disease in type 2 diabetes mellitus: current management guidelines. Arch Intern Med 163: 33-40.

60. Gonzalez-Ortiz M, Martínez-Abundis E, Robles-Cervantes JA, Ramirez-
Ramírez V, Ramos-Zavala MG (2011) Effect of thiamine administration on metabolic profile, cytokines and inflammatory markers in drug-naïve patients with type 2 diabetes. Eur J Nutr 50: 145-149.

61. Diabetes mellitus and hypoglycemia (2004) In: Current Medical Diagnosis and Treatment. Lange Publications 1146-1190.

62. University of Michigan Health System (2007) Management of type 2 diabetes mellitus.

63. Weber W, Kewitz H (1985) Determination of thiamine in human plasma and its pharmacokinetics. Eur J Clin Pharmacol 28: 213-219.

64. Ariaey-Nejad MR, Balaghi M, Baker EM, Sauberlich HE (1970) Thiamin metabolism in man. Am J Clin Nutr 23: 764-778.

65. Dursun E, Timur M, Dursun B, Süleymanlar G, Ozben T (2005) Protein oxidation in Type 2 diabetic patients on hemodialysis. J Diabetes Complications 19: 142

66. Cvetković T, Mitić B, Lazarević G, Vlahović P, Antić S, et al. (2009) Oxidative stress parameters as possible urine markers in patients with diabetic nephropathy. J Diabetes Complications 23: 337-342.

67. Goodman, Gillman (2006) Insulin Oral Hypoglycaemic agents and the the pharmacology of endocrine pancreas. In: The Pharmacological Basis of Therapeutics (11thedn). The McGraw-Hill companies, USA

68. Du X, Edelstein D, Obici S, Higham N, Zou MH, et al. (2006) Insulin resistance reduces arterial prostacyclin synthase and eNOS activities by increasing endothelial fatty acid oxidation. J Clin Invest 116: 1071-1080.

69. Du X, Edelstein D, Brownlee M (2008) Oral benfotiamine plus alpha-lipoic acid normalises complication-causing pathways in type 1 diabetes. Diabetologia 51 1930-1932.

70. Babaei-Jadidi R, Karachalias N, Ahmed N, Battah S, Thornalley PJ (2003) Prevention of incipient diabetic nephropathy by high-dose thiamine and benfotiamine. Diabetes 52: 2110-2120.

71. Brown NJ, Agirbasli M, Vaughan DE (1999) Comparative effect of angiotensinconverting enzyme inhibition and angiotensin II type 1 receptor antagonism on plasma fibrinolytic balance in humans. Hypertension 34: 285-290.

72. Osende JI, Badimon JJ, Fuster V, Herson P, Rabito P, et al. (2001) Blood thrombogenicity in type 2 diabetes mellitus patients is associated with glycemic control. J Am Coll Cardiol 38: 1307-1312. 